Artigos

Volume 11 - $2021 \mid$ n. 3

\title{
A Pesquisa sobre Custo-Aluno no Brasil: caminhos percorridos e possibilidades
}

\author{
Fernando Vizotto Galvão \\ Universidade de São Paulo (USP), São Paulo/SP - Brasil
}

\section{Resumo}

O artigo analisa a trajetória das pesquisas sobre custo-aluno conduzidas no contexto brasileiro. Partindo dos trabalhos produzidos na década de 1970 e chegando às pesquisas realizadas até o final da década de 2010, o artigo destaca algumas das contribuições metodológicas de cada estudo e tenta delinear, brevemente, as influências e as motivações associadas às pesquisas sobre custo-aluno produzidas no período. Além disso, tendo por base a produção recente sobre o tema, aponta possibilidades de caminhos a serem melhor explorados pela pesquisa nacional sobre custos educacionais.

Palavras-chave: Custo-Aluno. Financiamento da Educação. Recursos Educacionais.

\section{Research on Student Cost in Brazil: paths taken and possibilities}

\section{Abstract}

The article analyzes the trajectory of cost-student research conducted in the Brazilian context. Starting from the works produced in the 1970s and reaching the researches carried out until the end of the 2010s, the article highlights some of the methodological contributions of each study and tries to outline, briefly, the influences and motivations associated with the coststudent researches produced in the period. In addition, based on recent production on the topic, it points out possibilities for ways to be better explored by national research on educational costs.

Keywords: Cost per student. Education Financing. Educational Resources. 
A Pesquisa sobre Custo-Aluno no Brasil

\section{Introdução}

Nas últimas décadas, diversos trabalhos se dedicaram a produzir estimativas e análises sobre o que, no Brasil, tem sido chamado de custo-aluno. Pesquisas conduzidas em diferentes áreas (como na economia, na educação e na administração), tendo por base diferentes pressupostos e motivações e fazendo uso de diferentes técnicas de análise, têm apresentado uma série de estimativas sobre custos educacionais que têm sido úteis para a elaboração de avaliações e propostas acerca da alocação dos recursos educacionais no contexto brasileiro.

Além de revelarem tendências sobre custos por aluno em unidades de ensino que atendem estudantes de diferentes etapas e modalidades da educação básica, as pesquisas sobre o tema parecem refletir e ao mesmo tempo influenciar parte significativa do debate sobre financiamento da educação no Brasil desde a década de 1970. A proposta de Custo Aluno-Qualidade (CARREIRA; PINTO, 2007) talvez seja um dos principais exemplos desse tipo de dinâmica, que culmina em uma mudança de paradigma da política educacional.

Tendo em vista a existência de um número significativo de pesquisas nacionais sobre custo-aluno, mas também considerando a dificuldade de comparar valores de custos por aluno estimados de formas tão diferentes (como será visto adiante, entre outras coisas, há pouco acordo entre os diferentes autores sobre a composição de custos diretos e indiretos em educação), este artigo pretende explorar não os valores relativos ao custo-aluno nas pesquisas sobre o tema, mas sim algumas das características desses estudos no que diz respeito ao método empregado para a estimativa de custo e, principalmente, registrar as influências e motivações que permeiam cada pesquisa. Além disso, são apontadas algumas possibilidades de caminhos a serem seguidos em pesquisas futuras sobre custo-aluno no contexto brasileiro, tendo em vista a produção recente sobre o tema.

Diante do exposto, a seleção dos estudos que compõem este artigo teve como critérios: 1) pesquisas publicadas em periódicos ou em livros/capítulos de livros; 2) pesquisas que apresentam alguma novidade em relação à técnica ou à abordagem utilizada para a estimativa de custos educacionais (mensurados no nível das escolas); e 3) estudos que representam clivagens na pesquisa sobre custo-aluno, isto é, estudos que, provavelmente refletindo o contexto e as disputas sobre concepções de educação e sobre financiamento da educação, pareceram caracterizar uma nova tendência de pesquisa sobre custos educacionais no âmbito nacional. Dessa forma, este artigo não pretende fazer uma revisão exaustiva da literatura brasileira sobre custo-aluno, dedicando-se à análise dos trabalhos que pareceram representar bem os principais movimentos de pesquisa sobre o tema. É claro, contudo, que o juízo de valor implícito neste critério o torna sujeito à contestação, sendo sempre válido o debate sobre quais são ou não os principais movimentos de pesquisa em um campo, assim como sobre quais são os estudos que melhor representam ou não esses movimentos.

\section{Alguns apontamentos sobre custos e educação}

Ainda que tanto a educação escolar quanto a contabilidade de custos sejam antigas, tudo indica que a produção sistemática de estudos sobre custos em educação teve início no campo da economia, na década de 1960, quando Schultz $(1960 ; 1967)$ se propôs a identificar fatores que pudessem explicar padrões de crescimento econômico que não podiam ser 
explicados pelos fatores de produção tradicionais, como recursos naturais, capital e trabalho. A partir dos trabalhos de Schultz, que formula o que ficou conhecido como Teoria do Capital Humano ${ }^{1}$, a consideração dos anos de estudo da população como um fator explicativo da produtividade e do crescimento econômico dos países passou a influenciar a elaboração de teorias e estudos que tratam a educação como um investimento, que, como qualquer outro, está associado a benefícios e custos. A ideia já tinha sido antecipada por Adam Smith, ao especificar o que seria um dos itens do capital fixo, componente do "capital geral da sociedade", "cuja característica consiste em proporcionar renda ou lucro, sem circular ou mudar de proprietário":

Em quarto lugar, as habilidades úteis adquiridas por todos os habitantes ou membros da sociedade. A aquisição dessas habilidades para a manutenção de quem as adquiriu durante o período de sua formação, estudo ou aprendizagem, sempre custa uma despesa real, que constitui um capital fixo e como que encarnado na sua pessoa. Assim como essas habilidades fazem parte da fortuna da pessoa, da mesma forma fazem parte da sociedade à qual ela pertence. A destreza de um trabalhador pode ser enquadrada na mesma categoria que uma máquina ou instrumento de trabalho que facilita e abrevia o trabalho e que, embora custe certa despesa, compensa essa despesa com lucro (SMITH, 1996, p. 290).

Conforme será visto adiante, a análise dos custos educacionais empreendida nos estudos brasileiros influenciados pelos trabalhos de Schultz, geralmente dedicados a estimar as taxas de retorno da educação (tratada como investimento), costuma dividir os custos em diretos e indiretos, sendo os custos diretos relativos aos gastos públicos e privados empreendidos para a viabilização das atividades escolares de crianças e jovens de determinado contexto; e os custos indiretos relativos aos salários não recebidos pelos estudantes enquanto estes se dedicam aos estudos e não ao trabalho².

Outro tipo de concepção de custo costuma ser utilizado pela contabilidade de custos. Ainda que os métodos de custeio variem, geralmente a contabilidade trata o custo como a parcela dos recursos (em termos de valores monetários) que podem ser atribuídos à produção/elaboração de determinado bem ou serviço em determinado período. Sendo assim, ao menos no método de Custeio por Absorção (que geralmente faz uso de rateios para a atribuição de custos indiretos), custos diretos dizem respeito aos recursos que podem ser diretamente atribuídos à produção de determinado bem ou serviço, enquanto custos indiretos são aqueles que não podem ser associados com precisão a determinado produto ou a determinado serviço (pensando em um processo de produção industrial, custos diretos seriam

1 Como indicado, investigando os fatores que pudessem explicar diferenças de crescimento econômico entre países, Schultz desenvolve análise que atribui parte do crescimento econômico ao que ele chamou de Capital Humano, capital constituído, entre outras coisas, a partir da educação escolar: "Eu proponho tratar a educação como um investimento humano e tratar seus efeitos como uma forma de capital. Considerando que a educação se torna parte da pessoa que a recebe, eu vou me referir a isso como capital humano. Tendo em vista que se torna parte integral de uma pessoa, não pode ser comprado, vendido ou tratado como propriedade, tendo em vista nossas instituições. Ainda assim, se contribui para a realização de um serviço produtivo que agrega valor à economia, é uma forma de capital" (SCHULTZ, 1960, p. 561, grifo no original, tradução minha).

2 Tratando dos custos da educação, Schultz (1967, p. 21) propõe que sejam considerados como custos da educação não somente os desembolsos realizados pelas famílias e governos para o financiamento das atividades escolares, mas também os salários não recebidos pelos alunos, sendo estes referentes à remuneração que os alunos deixam de receber por estarem dedicando seu tempo aos estudos e não ao trabalho. 
aqueles relativos à matéria prima e aos salários do pessoal diretamente envolvido na produção de um bem, sendo exemplos de custos indiretos os salários de funcionários não diretamente envolvidos no processo de produção, aluguel, depreciação e manutenção de máquinas e equipamentos, sendo necessário o rateio destes últimos para a composição do custo total de produção) (sobre isso, ver MARTINS, 2003, p. 17-33)

Em relação à transposição da análise de custos para a análise de custos educacionais, além da dificuldade que essas diferentes concepções de custos geram para a comparação de estudos produzidos em diferentes áreas, vale notar que a análise de custos se desenvolve, na sua origem, para a mensuração de custos em contextos produtivos. Sendo assim, tanto na economia quanto na contabilidade ou na administração, a referência a custos diretos e indiretos parece tender a buscar em ambientes produtivos e/ou fabris a referência para estimar o que seriam custos diretos e indiretos no contexto educacional. Em geral, os estudos sobre custo-aluno classificam a despesa que pode ser atribuída a uma escola/etapa de ensino em determinado período como custo direto e, como indiretos, os custos externos à unidade de ensino (sejam os relativos à manutenção de diretorias de ensino e secretarias de educação, sejam os que dizem respeito ao custo dos salários não recebidos pelos estudantes enquanto se dedicam ao estudo), como se as escolas correspondessem a uma espécie de unidade produtiva em que um conjunto de insumos geraria um produto. Diante disso, entendese aqui que, ao menos levando em conta os métodos disponíveis na contabilidade de custos, estimativas de custo baseadas no Custeio Baseado em Atividades ${ }^{3}$ (e não no Custeio por Absorção), geralmente considerado mais apropriado para atividades relacionadas à prestação de serviços (ALONSO, 1999), talvez possam minimizar o constrangimento associado à realização de rateios e à necessidade de decidir sobre o que são custos diretos e indiretos tendo por base a referência principalmente a ambientes de produção, ainda que a aplicação do método seja geralmente mais trabalhosa e cara. Ou talvez, como atividade com características peculiares e com aspectos e consequências de difícil mensuração, o campo educacional precise, com o tempo, desenvolver uma abordagem própria para lidar com a valoração dos aspectos materiais e imateriais envolvidos em seu âmbito de atuação.

\section{A pesquisa sobre custo-aluno no brasil: da eficiência do gasto à qualidade do ensino}

Levy, Campino e Nunes (1970) empreenderam uma das primeiras pesquisas dedicadas à análise dos custos educacionais no contexto brasileiro. Alinhados aos trabalhos desenvolvidos por Schultz (1960; 1967) e Becker (1962), que instauraram a concepção de educação como investimento em Capital Humano, o estudo se dedicou a estimar os custos

3 Em linhas gerais, o Custeio Baseado em Atividades (ABC) estima o custo de bens ou serviços em duas etapas. Em um primeiro momento, os recursos utilizados na produção de bens ou serviços são direcionados às atividades que consomem esses recursos. Em um segundo momento, é feita a associação entre essas atividades e a elaboração dos produtos e serviços gerados por elas. Em resumo, parte-se do entendimento de que as atividades ou processos de trabalho consomem recursos e de que os produtos ou serviços "consomem" atividades. Esse método de custeio, que evita o uso de rateios, é apontado como útil por garantir uma alocação mais precisa dos custos indiretos, já que esses custos são associados diretamente às diferentes atividades exercidas por uma organização, não sendo alocados de forma arbitrária a um conjunto de bens ou serviços produzidos (sobre Custeio Baseado em Atividades, ver MARTINS, 2003, p. 60-72). 
sociais ${ }^{4}$ diretos (referentes às despesas correntes e de capital em que os governos e entidades privadas incorrem para a viabilização de serviços educacionais) e indiretos (que dizem respeito aos salários não recebidos pelos estudantes enquanto se dedicam aos estudos) da educação no estado de São Paulo, considerando diferentes etapas e modalidades de ensino, assim como procurou estimar as taxas de retorno da educação no contexto em pauta, tendo em vista que o conhecimento destas taxas de retorno contribuiria para a "[...] determinação de uma alocação ótima de recursos para a educação em geral, e, particularmente, dentro do setor educacional" (LEVY; CAMPINO; NUNES, 1970, p. 3).

Tratando especificamente da rede estadual de ensino do Estado de São Paulo, os autores tomaram por base informações contábeis obtidas na Secretaria Estadual de Educação, referentes às despesas correntes e de capital (incluindo não só as despesas das escolas, mas também as despesas realizadas pelas diretorias de ensino e por áreas administrativas da Secretaria da Educação), para estimar o custo médio por aluno matriculado na rede estadual. No caso da despesa de capital, vale notar que o estudo utilizou os valores estimados para prédios e construções das unidades de ensino e demais instalações da rede estadual de ensino como base para estimar o estoque de capital das escolas, não tendo sido feito um inventário de materiais, equipamentos e terrenos disponíveis. A partir disso, os autores aplicaram taxas de depreciação ao estoque de capital estimado, para que a parcela do estoque de capital correspondente ao período pudesse ser considerada no custo. Além disso, em linha com os estudos empreendidos na economia, os autores incluíram como parcela do custo de capital o custo de oportunidade, sendo esse custo referente ao valor do uso alternativo que poderia ser dado ao capital imobilizado nas escolas. Dessa forma, o custo de capital correspondeu à soma da depreciação do estoque de capital com o custo de oportunidade do capital imobilizado nas escolas (LEVY; CAMPINO; NUNES, 1970, p. 133136).

A distribuição percentual das parcelas do custo segundo categorias econômicas da despesa pública revela a importância que as despesas correntes assumiam nos custos educacionais no caso da rede estadual de educação de São Paulo: tanto para os anos iniciais e finais do Ensino Fundamental quanto para o Ensino Médio e para cursos técnicos, as despesas correntes correspondiam a aproximadamente $90 \%$ do total dos gastos (LEVY; CAMPINO; NUNES, 1970, p. 191). Além disso, ainda que as despesas com pessoal não tenham sido consideradas separadamente, os autores indicam que elas correspondiam a uma parcela significativa das despesas correntes (p. 151), resultado que está em linha com as pesquisas posteriores.

Diferente do estudo empreendido por Levy, Campino e Nunes (1970), as pesquisas seguintes que se dedicaram a estimar custos educacionais no contexto brasileiro procuraram estimar o custo por aluno no nível das escolas e não em termos de custo médio para redes de ensino. Castro, Assis e Oliveira (1972) realizaram o primeiro estudo sobre custos educacionais no nível da escola. Também sob influência da literatura preocupada principalmente com a eficiência na alocação dos recursos educacionais e com os retornos do investimento em educação, os autores justificam o estudo:

4 Os autores definem custos sociais como "[...] aqueles custos incorridos pela coletividade na manutenção e expansão do processo educacional", distinguindo-os dos custos privados, que seriam os suportados pelos estudantes e suas famílias (LEVY; CAMPINO; NUNES, 1970, p. 118). 
A Pesquisa sobre Custo-Aluno no Brasil

[...] a análise dos custos da educação nos permite identificar não somente os desperdícios óbvios e as irregularidades administrativas, mas também as áreas em que seria possível reduzir os dispêndios sem reflexos negativos na qualidade da educação oferecida pela escola. É exatamente este tipo de análise que tentaremos realizar na parte final deste trabalho (CASTRO; ASSIS; OLIVEIRA, 1972, p. 27).

Ainda que trate de custos no âmbito de escolas técnicas, que apresentam peculiaridades no que diz respeito a prédios, equipamentos e duração dos cursos, a pesquisa merece destaque por apresentar um rigor metodológico que pode servir de referência para pesquisas sobre o tema, mesmo no âmbito do ensino regular. Nesse sentido, merecem destaque: 1) a consideração do custo-aluno-hora, que permite a comparação do custo-aluno para cursos com diferentes períodos de duração (p. 36); e 2) o cuidado com a consideração de taxas de depreciação para móveis, equipamentos e prédios escolares, já que os usos escolares desses componentes do estoque de capital são diferentes dos usos em outros espaços, o que pode levar as escolas a terem níveis de depreciação específicos (CASTRO; ASSIS; OLIVEIRA, 1972, p. 48).

Em relação aos resultados, os autores obtiveram proporções de custo de capital (restrito ao custo de oportunidade e aos gastos com manutenção) por aluno relativamente maiores que o custo de capital para escolas de ensino regular, o que era esperado, considerando a existência de máquinas e equipamentos utilizados para o ensino nas escolas técnicas.

Em relação ao viés teórico e metodológico, vale destacar que as duas pesquisas tratadas até aqui se ampararam em um tipo de abordagem típico da microeconomia, que costuma analisar unidades produtivas a partir de uma relação entre insumos e produtos e em que a alocação considerada eficiente é aquela que produz o melhor resultado para dado nível de custo, ou aquela que minimiza o custo, dado determinado nível de produto ou resultado a ser obtido. Isto é,

Para que a análise econômica possa ser aplicada ao setor educacional necessário se torna que este seja entendido como uma unidade econômica integrada, dentro das categorias econômicas usuais. Assim, supõe-se que, dentro de um sistema econômico, a escola possui as características básicas de uma unidade de produção, que oferece serviços educacionais com a utilização de fatores de produção tais como professores, alunos, instalações físicas, etc., dentro de um dado nível tecnológico. Idealmente pois interessa obter o custo realizado do fluxo de serviços prestados por professores, bibliotecários, administradores, dos custos de manutenção e operação da escola (despesas correntes) e de parcelas referentes à depreciação e custo de oportunidade (taxa implícita de juros) do estoque de capital (despesas de capital) (LEVY; CAMPINO; NUNES, 1970, p. 119).

Outro tipo de abordagem de pesquisa sobre custos educacionais é seguido por Paro (1981), aparentemente o primeiro pesquisador ligado ao campo da educação a desenvolver uma pesquisa sobre o tema no Brasil. Preocupado com questões relativas à eficiência na alocação dos recursos orçamentários ( $p$. 9), mas também com aspectos como custos educacionais segundo "as classes de renda per capita" e segundo os "níveis de carência" dos alunos (p. 76-82), o autor se distancia, em alguma medida, das pesquisas empreendidas anteriormente.

Para estimar o custo por aluno de escolas de Ensino Fundamental e Médio da rede estadual de educação de São Paulo, o autor partiu de uma amostra de 66 escolas, distribuídas 
segundo regiões do estado e segundo determinadas características populacionais, e calculou os custos diretos (nesse caso, os custos diretos dizem respeito aos custos que podem ser atribuídos exclusivamente às escolas, ficando de fora os custos indiretos, que, no caso desta pesquisa, são considerados como aqueles em que Diretorias de Ensino e a sede da Secretaria da Educação incorrem para a manutenção de suas atividades) por aluno aprovado e por aluno matriculado, tendo por base, além de despesas correntes e de capital, despesas classificadas como sociais, sendo estas relativas aos gastos com "assistência nutricional, assistência médica e assistência odontológica” dos alunos (PARO, 1981, p. 20).

Além da inovação na classificação das despesas em que as estimativas dos custos se baseiam, vale destacar a não consideração dos custos de oportunidade (p. 15) e a opção por indicar como mais precisa a estimativa do custo por aluno aprovado ao final do ano, relativamente ao cálculo do custo por aluno matriculado, tendo em vista que, caso considerados os alunos matriculados para o cálculo do custo por aluno, "[...] não estaremos calculando com exatidão o custo do produto da 'empresa' escola, já que o objetivo desta é a produção de alunos com instrução suficiente para serem aprovados ou promovidos para a próxima série" (PARO, 1981, p. 61).

Em relação aos resultados obtidos, destacaram-se a predominância das despesas com pessoal nas escolas, que correspondem a $76 \%$ do custo por aluno (sendo que $60 \%$ dos custos dizem respeito aos salários dos docentes), e o menor peso das parcelas relativas às despesas de capital $(18,4 \%)$ e às despesas sociais $(2,85 \%)$. Além disso, os resultados indicaram certa associação entre o custo por aluno e as classes de renda per capita: considerando nesse caso o custo por aluno matriculado, o autor indica que os maiores valores de custo por aluno foram obtidos para escolas que se encontravam em regiões com maior renda per capita, sendo os menores valores de custo associados às classes de renda per capita mais baixas, ficando a sugestão de que o maior poder de pressão das famílias com mais recursos pode ter levado o setor público a direcionar mais recursos para as escolas das regiões em que essas famílias residiam (PARO, 1981, p. 76-79).

O final da década de 1980 marca o início de um período em que as pesquisas sobre custos educacionais parecem se dedicar principalmente a compreender as características e fatores que se associam ou que explicam diferentes níveis de custo por aluno nas escolas. Nesse caso, a preocupação parece estar menos relacionada à otimização de recursos, sendo o foco das pesquisas o estudo de contextos escolares variados, a partir de amostras nacionalmente representativas, o que poderia dar indícios sobre diferentes níveis de recursos necessários para a viabilização do ensino em escolas situadas em determinados contextos e que apresentassem determinadas características.

Nesse momento de transição do foco das pesquisas sobre custos educacionais, Xavier e Marques (1988) empreenderam estudo dedicado a estimar o custo direto de funcionamento de escolas públicas de $1^{\circ}$ grau (nesse caso, o custo direto dizia respeito ao custo que podia ser atribuído exclusivamente às unidades de ensino, sendo desconsiderados os custos indiretos, relativos à manutenção das atividades de Diretorias de Ensino e de Secretarias de Educação; ademais, sendo estimados somente os custos de funcionamento das escolas, foram desconsiderados os custos relativos à instalação e depreciação dos prédios escolares), tendo por base uma amostra nacional de escolas. O trabalho tinha como objetivo "[...] auxiliar a tomada de decisão e o planejamento educacional [...]", no sentido de estabelecer uma 
A Pesquisa sobre Custo-Aluno no Brasil

medida de custo por aluno que possibilitasse a comparação de custos entre as diferentes regiões do país, o que subsidiaria "[...] uma melhor alocação federal de recursos" (XAVIER; MARQUES, 1988, p. 9).

A pesquisa, conduzida no âmbito no Ministério da Educação, procurou abranger escolas com diferentes características no que diz respeito à região do País, rede de ensino (municipal ou estadual), localização urbana ou rural, tamanho (em número de alunos), número de salas de aula e a estarem localizadas no interior dos estados ou nas capitais. O objetivo era contemplar fatores que poderiam estar associados a variações no custo por aluno a ser estimado.

Em relação aos resultados, a pesquisa inovou ao fazer uma aproximação entre financiamento da educação e resultados educacionais: comentando o alto gasto por aluno com docentes e não docentes das escolas do Rio Grande do Sul, relativamente às escolas dos outros estados da Região Sul do País, os autores sugeriram que seria esperado um melhor desempenho escolar dos alunos gaúchos relativamente aos demais alunos da região, mantidos constantes outros fatores (XAVIER; MARQUES, 1988, p. 39).

Além da aproximação entre financiamento da educação e resultados educacionais, a pesquisa pareceu antever o a elaboração dos estudos que posteriormente se dedicaram à estimativa do Custo Aluno-Qualidade (CARREIRA; PINTO, 2007), indicando a necessidade não somente de trabalhos que estimassem os custos de escolas existentes/em funcionamento, mas de trabalhos dedicados a estimar o custo por aluno necessário para que escolas operassem em condições de oferecer ensino de qualidade. Nas palavras dos autores:

Os custos apresentados dizem respeito ao que existe na escola e não àquilo que deveria existir. Pode ser que a diferença de custos esteja refletindo diferenças qualitativas, e que a escola mais cara seja, de fato, a mais bem equipada e (consequentemente?) a de melhor ensino. Há necessidade, portanto, de serem efetuados estudos que definam padrões de escola (XAVIER; MARQUES, 1988, p. 49).

Simultaneamente à elaboração de estudos que já atentavam para a necessidade de estimativas de custo por aluno que representassem padrões ou níveis de recursos que viabilizassem uma melhoria do ensino oferecido nas escolas, eram travadas as discussões que dariam origem ao entendimento sobre a educação que deveria ser garantida pelo Estado a partir do final dos anos 1980, entendimento consubstanciado principalmente na Constituição Federal e na Lei de Diretrizes e Bases da Educação (LDB).

No que diz respeito a níveis de recursos a serem destinados à educação pública, para este trabalho interessam principalmente os dois artigos transcritos abaixo, da LDB, pois explicitam o entendimento da legislação acerca da relação entre recursos a serrem destinados ao financiamento das escolas e qualidade do ensino.

Art. $4^{\circ} \mathrm{O}$ dever do Estado com educação escolar pública será efetivado mediante a garantia de: [...]

IX - padrões mínimos de qualidade de ensino, definidos como a variedade e quantidade mínimas, por aluno, de insumos indispensáveis ao desenvolvimento do processo de ensino-aprendizagem.

Art. 74. A União, em colaboração com os Estados, o Distrito Federal e os Municípios, estabelecerá padrão mínimo de oportunidades educacionais para o ensino fundamental, baseado no cálculo do custo mínimo por aluno, capaz de assegurar ensino de qualidade. 
A Pesquisa sobre Custo-Aluno no Brasil

Parágrafo único. O custo mínimo de que trata este artigo será calculado pela União ao final de cada ano, com validade para o ano subsequente, considerando variações regionais no custo dos insumos e as diversas modalidades de ensino (BRASIL, 1996).

Como será visto adiante, a explicitação de um vínculo entre recursos a serem destinados à educação e a viabilização de um ensino de qualidade vai influenciar a pesquisa sobre custo-aluno produzida a partir dos anos 2000, ainda que diversas concepções de qualidade do ensino permaneçam em disputa.

Em relação ao vínculo entre recursos e qualidade do ensino, vale notar que, enquanto o artigo $4^{\circ}$ instaura o entendimento de que padrões de qualidade do ensino são definidos como a própria disponibilidade de determinado nível e variedade de recursos/insumos por aluno a serem garantidos pelo Estado, o artigo $74^{\circ}$ aponta para os recursos mínimos por aluno como meio para a viabilização de um ensino de qualidade. Como observa Galvão (2016, p. 21):

\begin{abstract}
Estes dois artigos, portanto, explicitam o vínculo entre recursos financeiros a serem destinados às escolas e o cumprimento do direito à educação, pois ou apontam para tais recursos como indispensáveis para a garantia de ensino de qualidade ou instauram o entendimento de que a qualidade do ensino se consubstancia nos recursos destinados à educação. Isto é, se o direito à educação só é cumprido em sua integralidade com ensino de qualidade, pode-se dizer que, para a LDB, a destinação de recursos à educação constitui não somente condição para o cumprimento do direito à educação, mas a própria realização deste direito.
\end{abstract}

Nessa conjuntura de entendimentos acerca dos recursos a serem destinados ao financiamento das escolas, o Instituto Nacional de Estudos e Pesquisas Educacionais Anísio Teixeira (INEP) promoveu/coordenou uma das pesquisas mais abrangentes já feitas sobre custos educacionais no contexto brasileiro. Denominada Levantamento do custo-aluno-ano em escolas que oferecem condições para a oferta de um ensino de qualidade, o estudo (iniciado em 2003) contou com a participação de grupos de pesquisadores de diferentes regiões do País e resultou em uma série de publicações (VERHINE, 2006; CAMARGO et al., 2006; VERHINE; MAGALHÃES, 2006; GOUVEIA et al., 2006; FARENZENA, 2005; OLIVEIRA, 2006). Seguindo o caminho delineado por Xavier e Marques (1988), a pesquisa explicitou a intenção de estabelecer uma relação entre o custo por aluno e a qualidade do ensino oferecido em cada escola, algo recente na pesquisa brasileira sobre custos educacionais (FARENZENA, 2005, p. 7).

Tendo em vista o objetivo de selecionar escolas que apresentassem um conjunto de características que permitisse classificá-las como escolas com condições de oferecer um ensino de qualidade, a amostra de 95 escolas foi constituída a partir do Índice de Escolha de Escolas (IEE) ${ }^{5}$, índice que na prática revela a concepção de qualidade do ensino que permeou a pesquisa, já que as escolas escolhidas para compor a amostra deveriam apresentar valores satisfatórios para os indicadores que compunham o IEE. Os indicadores/dimensões que serviram de base para a elaboração do IEE foram:

Infraestrutura: serviços básicos, equipamentos pedagógicos, infraestrutura pedagógica, equipamentos básicos, infraestrutura básica; Perfil do docente: taxa de docentes com

5 Além do IEE, cada grupo de pesquisadores pôde considerar a inclusão de escolas a partir de informações disponíveis em cada rede sobre a existência de escolas de qualidade que não foram selecionadas com base no índice desenvolvido pelo INEP (FARENZENA, 2005, p. 15). 
A Pesquisa sobre Custo-Aluno no Brasil

formação superior; Perfil do aluno: taxa de aprovação e taxa de adequação idade/série; Perfil da oferta: número médio de horas-aula diárias e número médio de alunos por turma (FARENZENA, 2005, p. 15).

Vale notar que a concepção de qualidade do ensino oferecido, que norteou a escolha das escolas que terão o custo-aluno estimado, ainda que concentrada na disponibilidade de recursos, incluiu a "taxa de aprovação", indicador geralmente classificado como relativo a resultados educacionais. Sendo assim, pode-se dizer que a escolha de escolas extrapolou a dimensão de condições de oferta de ensino de qualidade e incorporou uma medida que representa um dos resultados possíveis de um ensino de qualidade (GALVÃO, 2016, p. 23).

Em relação aos custos das escolas, foram estimados os custos de funcionamento (despesas correntes como salários, gastos com alimentação dos alunos, água, luz etc.) e de implantação (valores estimados para prédios e terrenos, entre outros) das escolas, ficando de fora os custos indiretos associados à administração central dos sistemas de ensino (Diretorias de Ensino e Secretarias de Educação). Em especial no caso dos valores relativos aos equipamentos disponíveis nas escolas e aos prédios escolares, vale destacar que, ao menos no caso de parte das publicações que reportaram resultados regionais (isto é, que trataram dos valores estimados no âmbito de determinado estado) (FARENZENA, 2005), a consideração dos valores totais de equipamentos e prédios no custo médio por aluno e não do valor relativo à parcela de depreciação anual aproxima os valores estimados mais do conceito de gastos por aluno do que do conceito de custo por aluno ${ }^{6}$. De toda forma, tendo em vista a preocupação em conhecer os valores associados à implantação e ao funcionamento das escolas, pode-se dizer que a pesquisa se aproximou dos trabalhos dedicados à estimativa do Custo Aluno-Qualidade Inicial (CAQi) e do Custo Aluno-Qualidade (CAQ), ainda que estes últimos optem por tratar separadamente os custos de funcionamento/manutenção e de implantação das escolas, não totalizando essas parcelas em termos de custos totais (já que os gastos com implantação são realizados de uma vez, podendo ser incorporados aos custos anuais de funcionamento na forma de depreciação). E de fato, como registram Carreira e Pinto (2007, p. 39), a pesquisa iniciada pelo INEP em 2003 tinha como um de seus propósitos produzir informações que contribuíssem para a elaboração de uma proposta de Custo Aluno-Qualidade.

$O$ trabalho de consolidação das informações levantadas em cada estado (cujas estimativas de custo-aluno deram origem a publicações próprias) resultou em uma publicação que procurou explorar as principais tendências relativas aos valores estimados para os custos educacionais estimados, considerando a amostra nacional de escolas (VERHINE, 2006). Entre as principais características e resultados desse trabalho, destacam-se: 1) a consideração não somente do custo das escolas, mas também a caracterização das escolas

6 Martins (2003, p. 17) aponta que o conceito de gasto está associado ao sacrifício financeiro relativo à "compra de um produto ou serviço qualquer". No caso do orçamento público, fonte dos recursos de que as pesquisas sobre custo-aluno tratam, Alves (2012) aponta que gastos e despesas são termos que representam uma mesma ideia, tendo em vista que a despesa pública pode ser definida como "o conjunto de dispêndios do Estado no atendimento dos serviços e encargos assumidos no interesse da população" (SILVA, 2009, p. 240). Assim, no caso das escolas, "[...] pode-se dizer que a despesa ou o gasto público com educação pública trata de todo o recurso financeiro utilizado para implantação e manutenção de escolas e redes de ensino, mas só seria considerado custo o gasto público que pode ser atribuído a um conjunto determinado de escolas em determinado período" (GALVÃO, 2016, p. 33). No caso de prédios e equipamentos disponíveis nas escolas, que podem durar anos, a parcela de custo a ser atribuída a cada escola em cada período corresponde à fração do valor do bem que seja equivalente à fração período de uso/durabilidade estimada do bem considerado. 
no que diz respeito às condições de funcionamento e de sua gestão (as escolas foram caracterizadas, por exemplo, quanto à existência e condições de uso de determinados espaços, quanto à situação funcional, experiência e formação de docentes e diretores e quanto ao número de alunos por turma (p. 34-41), caracterização que viabiliza a análise acerca das opções feitas quanto ao uso dos recursos disponíveis nas escolas; 2) a criação das categorias Custo-Aluno - Manutenção do Ensino (CA-MAN) e o Custo-Aluno - Econômico (CA-ECO), o primeiro agregando as despesas com pessoal, material de consumo, material permanente e outros insumos, e o segundo incorporando, além dessas despesas, os custos associados às instalações (terreno e prédio) e à merenda escolar (VERHINE, 2006, p. 48); 3) a consideração da depreciação de prédios e do custo de oportunidade dos terrenos para a estimativa do CA-ECO (opção metodológica diferente da que foi seguida na maior parte dos estudos conduzidos nos oito estados que tiveram escolas selecionadas para as pesquisas regionais); 4) a observação de grande variação do custo-aluno (tanto para o CA-MAN quanto para o CA-ECO) para a amostra considerada (após a exclusão de dois outliers, que apresentavam valores de terreno muito acima da média da amostra, o CA-MAN médio estimado foi de $\mathrm{R} \$ 1.697,75$ e o CA-ECO de $\mathrm{R} \$ 2.020,69$ para as 93 escolas restantes, sendo o menor e maior valor de custo por aluno de $\mathrm{R} \$ 254,22$ e $\mathrm{R} \$ 7.879,11$, respectivamente, no caso do CA-MAN) (p. 52); 5) a constatação de que os menores valores de custo por aluno estavam associados a estados/regiões que apresentavam menores níveis de desenvolvimento econômico (p. 52); 6) o maior peso do custo relativo ao pagamento de salários, em linha com os achados das demais pesquisas sobre custos educacionais (p. 53); 7) o maior peso relativo de despesas com prédios, terrenos e materiais de consumo no caso de escolas de educação infantil, comparativamente às outras etapas da educação básica ( $p$. 58); e 8) a construção de uma subamostra, de 33 escolas que atendiam a parâmetros exigentes quanto a determinadas características (como estado de conservação do prédio, formação dos docentes e número de alunos por turma, entre outros), o que evidenciou certa tendência de relação entre maiores valores para o custo por aluno estimado e melhores condições para a oferta de um ensino de qualidade (VERHINE, 2006, p. 61-61).

Como já adiantado, a pesquisa conduzida pelo INEP, cujos principais resultados foram publicados em 2006, aproximou-se em alguma medida dos estudos e debates que, conduzidos por organizações da sociedade civil e capitaneados principalmente pela Campanha Nacional pelo Direito à Educação ${ }^{7}$, resultaram na proposta do Custo AlunoQualidade Inicial (CAQi) (CARREIRA; PINTO, 2007; PINTO, 2006). Tal proposta consiste em uma estimativa de recursos a serem destinados às escolas que rompe com a prática de restringir a qualidade do ensino aos escassos recursos disponíveis (OLIVEIRA; ARAUJO, 2005, p. 18).

Atendendo ao disposto na legislação brasileira que trata do financiamento da educação pública (que aponta para o dever de definição de um custo mínimo por aluno que garanta um ensino de qualidade), o CAQi, conforme delineado pela Campanha Nacional pelo Direito à

\footnotetext{
A Campanha Nacional pelo Direito à Educação “[...] é uma articulação que surgiu em 1999, com o objetivo de somar diferentes forças políticas pela efetivação dos direitos educacionais garantidos em lei e reúne um grande número de organizações e movimentos com atuação na área da educação, dos direitos da infância e juventude, dos direitos humanos, dos direitos das mulheres, desenvolvimento comunitário, direitos da população negra e indígena, entre outros" (PINTO, 2006, p. 210). Mais informações sobre a Campanha Nacional pelo Direito à Educação podem ser obtidas em: https://campanha.org.br/. Acesso em: 02 jun. 2019.
} 
A Pesquisa sobre Custo-Aluno no Brasil

Educação, destaca-se, entre outras coisas, pela construção participativa de uma proposta de valores de custo por aluno que devem ser praticados para que um ensino de qualidade possa ser viabilizado. Além do processo participativo, a proposta ainda incorpora diferentes dimensões do que pode ser compreendido como qualidade em educação (escapando de certa tendência de restringir a concepção de qualidade em educação ao desempenho dos alunos em testes padronizados), o que se reflete na incorporação de insumos relacionados à infraestrutura das escolas, aos trabalhadores e trabalhadoras que atuam na educação, à gestão democrática de escolas e sistemas de ensino e ao acesso e à permanência dos alunos nas escolas (CARA et al., 2018; CARREIRA; PINTO, 2007; PINTO, 2006).

Em linhas gerais, o CAQi, considerando o que seria um atendimento escolar típico para cada etapa e modalidade da educação básica - tendo em vista padrões relativos ao tamanho de escolas e de turmas, à remuneração, jornada de trabalho e formação continuada a ser garantida aos profissionais que atuam nas escolas, aos espaços e materiais que devem existir em cada escola, à jornada diária de permanência dos alunos nas escolas e às atividades que cada escola precisa desenvolver tendo em vista seu projeto pedagógico, padrões esses a serem garantidos para que seja viável um patamar mínimo de qualidade do ensino -, consiste na realização de estimativas de custos anuais de manutenção e atualização das escolas (os custos de implantação das escolas não são incorporados ao cálculo do CAQi, já que esses custos, relativos a aquisição de terreno, construção do prédio escolar, compra de equipamentos e material permanente, são realizados uma única vez, em um período relativamente curto de tempo) (GALVÃO, 2018; CARREIRA; PINTO, 2007; PINTO, 2006). Esses custos, calculados a partir dos insumos que devem compor uma escola para que ela tenha condições de ofertar um ensino de qualidade, que servem de referência tanto para o montante de recursos a ser destinado a cada escola quanto para o volume de recursos a serem encaminhados à educação básica como um todo (geralmente tratado em termos de percentuais do Produto Interno Bruto (PIB) a ser aplicado em educação), são estimados como valores mínimos, mas não ideais. Nesse sentido, o CAQi se diferencia do $C A Q$, que incorpora não só os insumos/recursos mínimos que viabilizariam o cumprimento do direito à educação, mas os recursos que seriam recomendáveis, tendo em vista padrões de oferta do ensino mais exigentes, com características mais próximas às de países que possuem sistemas de ensino relativamente mais desenvolvidos (CARA et al., 2018, p. 17-19).

Ainda que a incorporação do CAQi e do CAQ nas estratégias da meta 20 do Plano Nacional de Educação (PNE 2014-2024) represente a consolidação de uma necessária mudança de lógica no financiamento da educação no País, indicando que as escolas passariam a ser financiadas tendo por base os recursos necessários para que o direito à educação se realize para todos, parece possível dizer que a efetiva implementação do CAQi e do CAQ dependerá de permanente mobilização, tendo em vista o contexto no qual o PNE 2014-2024 tem se desenvolvido. De toda forma, independentemente das disputas em torno do financiamento da educação no Brasil, vale destacar o CAQi/CAQ como uma importante mudança na forma como são compreendidos e representados os custos educacionais no País. 


\section{A pesquisa sobre custo-aluno no brasil: caminhos a explorar}

Após o movimento de pesquisa sobre custo-aluno que culminou na elaboração do Custo Aluno-Qualidade, a proliferação de avaliações em larga escala dedicadas à mensuração do desempenho de estudantes em testes (ver BONAMINO; SOUSA, 2012), a influência de pesquisas desenvolvidas principalmente na economia, que procuram estabelecer uma correlação entre despesas municipais com educação e desempenho (MONTEIRO, 2015; MENEZES-FILHO; OLIVEIRA, 2014; DIAZ, 2012; AMARAL, 2011) e, em alguma medida, a influência de estudos que procuram estimar custos educacionais tendo em vista o desempenho dos estudantes (KIMBALL, 2009; PICUS et al., 2008; CONLEY; PICUS, 2003; ODDEN et al., 2003; PICUS, 2000; PICUS; PETERNICK, 1998), talvez expliquem, em parte, o surgimento de estudos que procuram associar o custo-aluno (mensurado no nível das escolas) ao desempenho de estudantes em testes.

Em um desses estudos, Amâncio-Vieira et al. (2015) estimaram o custo direto ${ }^{8}$ por aluno em 67 escolas de Ensino Fundamental (anos iniciais) do município de Londrina/PR. Por meio de análise de regressão, estimaram a relação entre as categorias de custo consideradas no estudo e a média de desempenho dos alunos nos testes de português e matemática da Prova Brasil (tendo por base dados de custo e desempenho para o ano de 2011). Entre os resultados, os autores indicaram existir uma relação positiva entre a experiência dos docentes e o desempenho dos estudantes e negativa tanto entre custos sociais (relativos às despesas com transporte e merenda) e desempenho quanto entre custos administrativos (relativos às despesas com manutenção, limpeza, segurança e remuneração de pessoal administrativo, entre outras) e desempenho. Os autores indicaram, contudo, que a existência de correlação entre custos pedagógicos (relativos aos salários de professores e material de consumo) e a variável relativa à experiência dos docentes implicou a exclusão da variável de custos pedagógicos da regressão. Além disso, vale notar que a não consideração de variáveis que dizem respeito ao nível socioeconômico dos alunos pode implicar algum nível de viés nas estimativas (por exemplo, caso as escolas com maiores custos sociais atendam estudantes de menor nível socioeconômico, é possível que uma relação negativa entre custos sociais e desempenho esteja refletindo, na verdade, uma relação entre o nível socioeconômico dos estudantes e o desempenho).

Em outra pesquisa do tipo, Galvão (2016), apontando os problemas que estimativas baseadas em dados agregados (por município) de gastos com educação e desempenho em testes podem apresentar, estimou o custo por aluno com pessoal, segundo as funções exercidas por cada funcionário (a Tabela 1 indica as categorias de gasto utilizadas na pesquisa), das escolas da rede municipal de ensino de São Bernardo do Campo/SP. Tendo por base 55 unidades de ensino que ofereciam exclusivamente os anos iniciais do Ensino Fundamental, o estudo explorou as relações entre os custos estimados (para o ano de 2013) e o desempenho dos estudantes em matemática na Prova Brasil de 2013, por meio de análise

8 Nesse caso, os autores consideraram como custo direto as despesas correntes que puderam ser atribuídas diretamente às escolas, não sendo considerados custos relativos à depreciação de equipamentos e prédios escolares (p. 178). Os custos diretos de cada escola foram classificados como "[...] custos pedagógicos (remuneração dos professores e custo com material de consumo), sociais (custos com transporte e merenda) e administrativos (custos para o funcionamento da estrutura escolar, como custos com manutenção, limpeza, segurança, remuneração dos técnico-administrativos, entre outros)" (AMÂNCIO-VIEIRA et al., 2015, p. 178). 
de regressão. Entre outros achados, o autor reporta que os dados desagregados de salários, segundo a função que cada profissional exerce na escola, apontam relações entre gastos e desempenho que os dados de gastos agregados com pessoal não revelam. Além disso, são indicadas relações positivas e estatisticamente significantes entre as despesas com salários de coordenadores pedagógicos e o desempenho dos alunos em matemática (controlados outros tipos de gastos e o nível socioeconômico dos alunos).

Tabela 1 - Categorias de gastos definidas a partir das funções exercidas pelos educadores da rede municipal de ensino de São Bernardo do Campo

\begin{tabular}{l} 
Gastos diretamente relacionados ao ensino \\
\hline Desenvolvimento do currículo básico \\
Professores \\
Auxiliares de classe \\
Estagiários \\
Desenvolvimento de atividades de ensino - Ed. Especial \\
Professores Ed. Especial \\
Estagiários Ed. Especial \\
Espaço para pesquisa, leitura e ensino (biblioteca) \\
Orientação e suporte às atividades de ensino e \\
aprendizagem \\
Coordenação pedagógica \\
Suporte aos alunos e professores (monitoria) \\
\hline Gastos indiretamente relacionados ao ensino \\
\hline Gestão escolar \\
Direção da escola \\
Apoio operacional e administrativo
\end{tabular}

Rocha e Funchal (2019) estimaram a relação entre custos escolares diretos ${ }^{9}$ e o desempenho de alunos de escolas públicas no Exame Nacional do Ensino Médio (ENEM), também por meio de análise de regressão. Tendo por base 32 escolas estaduais de Ensino Médio do estado do Espírito Santo, o estudo reporta associações positivas e estatisticamente significantes entre o desempenho dos estudantes na prova de Linguagens e Códigos e custos com limpeza e conservação das escolas e entre o desempenho em matemática e os custos com salários de professores, salários de diretores, transporte escolar, água e energia e com o Programa Dinheiro Direto na Escola (PDDE). As estimativas consideraram variáveis não relacionadas aos custos escolares, sendo parte delas relativas ao nível socioeconômico dos alunos.

Como é possível notar, os três trabalhos indicados, que procuraram estabelecer relações entre custos educacionais e desempenho dos estudantes em testes de larga escala, apresentaram como principal restrição o número de observações. Ademais, nenhum deles

9 Assim como Amâncio-Vieira et al. (2015, p. 298), a pesquisa considera como custo direto o conjunto de despesas correntes que pode ser atribuído a cada unidade de ensino. As variáveis que representam os custos considerados são: "[...] salários de professores em regência de classe, salários de pessoal lotado em área administrativa da escola, salários de diretor, afastamentos do trabalho, vigilância patrimonial, alimentação escolar, transporte escolar, Programa Estadual Dinheiro Direto na Escola (Pedde), água e energia". Vale notar que, no caso do Programa Dinheiro Direto na Escola, não é possível distinguir se esses recursos foram ou não aplicados, transformando-se, de fato, em custo, já que o Programa representa uma fonte de recursos e não um custo das escolas. 
A Pesquisa sobre Custo-Aluno no Brasil

captou todos os custos em que as escolas incorrem para o desenvolvimento de suas atividades. Essas restrições parecem ser de difícil superação enquanto os sistemas de custo, alinhados a mecanismos de transparência, não viabilizarem informações sobre custos correntes e de capital por unidade de ensino.

Além do exposto, parecem existir ainda dois caminhos importantes a serem explorados pelas pesquisas sobre custo-aluno. O primeiro deles diz respeito à análise de desigualdades de custos entre escolas de uma mesma rede de ensino e até mesmo entre alunos ou grupos de alunos em uma mesma escola (esse tipo de análise poderia ser viabilizado, por exemplo, pela investigação da distribuição do uso do tempo de docentes e não docentes entre os alunos ou entre grupos de alunos, assim como pela análise da distribuição dos alunos entre turmas/professores). Ao menos no caso das desigualdades entre escolas de uma mesma rede de ensino, algumas das pesquisas citadas já indicaram que esse é um caminho a ser explorado: tanto Paro (1981) quanto Amâncio-Vieira et al. (2015), Galvão (2016) e Rocha e Funchal (2019) indicaram existir grande variação no custo por aluno entre as escolas da rede de ensino analisada em cada pesquisa. Esses estudos, contudo, não chegaram a investigar os motivos das desigualdades de custos observada.

Cardoso (2018), analisando o custo-aluno relativo aos salários dos educadores de 379 escolas municipais de Curitiba/PR, dedicou-se principalmente ao estudo da variação do custo estimado para as escolas consideradas na análise. Tendo por base as informações coletadas da folha de pagamentos do município de Curitiba do mês de outubro de 2013 e os dados do Censo Escolar de 2013, o estudo mostrou que, mesmo quando são comparadas as mesmas etapas da educação básica, as escolas apresentaram uma variação relevante de custo por aluno, no que diz respeito a salários. O estudo apontou também que parte da variação do custo por aluno pode estar relacionada a diferenças de necessidades de recursos, sendo, por exemplo, os custos de escolas exclusivamente de Educação Especial significativamente maiores que os custos das demais.

Nesse sentido, além das diferenças que podem ser motivadas por diferenças de necessidade de recursos (como pode ocorrer no caso de escolas com grande quantidade de alunos que precisam de atendimento especial ou no caso de escolas que atuam em período integral), vale destacar que a desigualdade de custo por aluno pode ocorrer tanto no sentido de reforçar desigualdades, como sugeriu Paro (1981), quanto no sentido de viabilizar um tratamento equitativo dos estudantes, por meio da garantia de mais recursos para escolas em que as possibilidades de aprendizagem dos alunos possam ser afetadas negativamente por sua condição social.

O estudo da variação de custos educacionais em função do nível socioeconômico dos alunos pode constituir outro caminho a ser melhor explorado em futuras pesquisas sobre custo-aluno. O tema é relativamente comum na literatura internacional que trata de custos e financiamento da educação (SCHWARTZ; RUBENSTEIN; STIEFEL, 2009; ODDEN, 2009; ROSS; LEVACIC, 1999), mas tudo indica que no contexto brasileiro o tema pode ser melhor explorado. Em um contexto de desigualdade social e em que a aprendizagem dos alunos está associada ao nível socioeconômico, pesquisas que viabilizem propostas de alocação de recursos adicionais para unidades de ensino que atendem estudantes que precisam de maior suporte da escola para que as melhores possibilidades de aprendizagem sejam garantidas (que pode se traduzir, entre outras coisas, em maior necessidade de atividades de reforço 
A Pesquisa sobre Custo-Aluno no Brasil

escolar no contraturno, em turmas menores, em maior tempo de permanência na escola, em maiores gastos com alimentação e transporte escolar ou em aulas de português para crianças e adultos que vieram de outros países) parecem ser necessárias e bem-vindas.

\section{Considerações finais}

O artigo procurou fazer uma análise do que pareceram ser as principais tendências de pesquisa sobre custos educacionais no contexto brasileiro nas últimas décadas. Entre outras coisas, pode-se notar que os estudos sobre custo-aluno são produzidos por pesquisadores de diferentes áreas de atuação, sendo frequentes os trabalhos ligados aos campos da economia, da educação e da administração. Essa posição de fronteira entre diferentes campos (entendendo fronteira como um espaço de trocas e não de limites) é positiva por gerar olhares diversos sobre o tema, mas a multiplicidade de abordagens, inclusive metodológicas, também implica a dificuldade de comparação dos resultados entre as pesquisas (a variação do que é considerado como custo direto e indireto talvez seja o melhor exemplo desse tipo de dificuldade).

Em linhas gerais, foi possível notar que, inicialmente, a pesquisa sobre custo-aluno no Brasil ocupava-se principalmente com questões relativas à eficiência dos gastos com educação, sendo também presente a preocupação com as taxas de retorno que tais gastos poderiam ter. Após esse primeiro movimento, a pesquisa sobre custo-aluno passou a explorar como e em que medida os recursos a serem destinados à educação poderiam viabilizar condições para que as escolas oferecessem um ensino de qualidade, movimento que talvez tenha como sua maior representação a elaboração dos estudos que tratam do Custo AlunoQualidade. Por fim, foram apontadas três possibilidades de caminhos de pesquisas futuras sobre custos educacionais no contexto brasileiro: 1) estudos que busquem correlacionar estimativas de custo-aluno com resultados educacionais, em especial com o desempenho dos alunos em testes (ainda que diversas ressalvas precisem ser feitas sobre esse tipo de abordagem); 2) pesquisas dedicadas à análise de diferenças de custo-aluno entre escolas de uma mesma rede de ensino e mesmo entre grupos de estudantes de uma mesma escola; e 3) trabalhos dedicados a explorar como o custo-aluno pode variar em função do nível socioeconômico dos estudantes, sendo esse tipo de abordagem relevante para a viabilização de propostas de alocação de recursos que contribuam para a redução de desigualdades escolares entre alunos de diferentes condições sociais.

\section{Referências}

ALONSO, M. Custos no serviço público. Revista do Serviço Público, Brasília, v. 50, n. 1, p. 37-63, jan./mar. 1999.

ALVES, T. Desenvolvimento de um modelo de previsão de custos para planejamento de sistemas públicos de educação básica em condições de qualidade: uma aplicação a municípios de Goiás. 2012. Tese (Doutorado em Administração) - Faculdade de Economia, Administração e Contabilidade da USP, São Paulo, 2012.

AMÂNCIO-VIEIRA, S. F.; BORINELLI, B.; NEGREIROS, L. F.; DALMAS, J. C. A relação entre o custo direto e desempenho escolar: uma análise multivariada nas escolas de ensino 
fundamental de Londrina/PR. Educação em Revista, Belo Horizonte, v. 31, n. 1, p. 169-194, jan./mar. 2015.

AMARAL, L. F. L. E. Os determinantes dos gastos educacionais e seus impactos sobre a qualidade do ensino. 2011. Dissertação (Mestrado em Economia) - Universidade de São Paulo, São Paulo, 2011.

BECKER, G. Investiment in human capital: a theoretical analysis. Journal of Political Economy, Part 2: Investiment in Human Beings, Chicago, v. 70, n. 5, p. 9-49, 1962.

BONAMINO, A.; SOUSA, S. Z. Três gerações de avaliação da educação básica no Brasil: interfaces com o currículo da/na escola. Educação e Pesquisa, São Paulo, v. 38, n. 2, p. 373388, abr./jun. 2012.

BRASIL. Lei $n^{\circ}$ 9.394, de 20 de dezembro de 1996. Estabelece as Diretrizes e Bases da Educação Nacional. Diário Oficial da União, Brasília, 1996. Disponível em: http://www.planalto.gov.br/ccivil_03/leis//9394.htm. Acesso em: 20 dez. 2019.

CAMARGO, R. B.; OLIVEIRA, J. F.; CRUZ, R. E.; GOUVEIA, A. B. Problematização da qualidade em pesquisa de custo-aluno-ano em escolas de educação básica. Brasília: INEP, 2006.

CARA, D. et al. CAQi e CAQ no PNE: quanto custa a educação pública de qualidade no Brasil? São Paulo: Campanha Nacional pelo Direito à Educação, 2018.

CARDOSO, J. A. Uma análise do custo-aluno em escolas de uma rede municipal de ensino. FINEDUCA - Revista de financiamento da educação, Porto Alegre, v. 8, n. 7, 2018.

CARREIRA, D.; PINTO, J. M. R. Custo aluno-qualidade inicial: rumo à educação pública de qualidade no Brasil. São Paulo: Global, 2007.

CASTRO, C. M.; ASSIS, M. P.; OLIVEIRA, S. F. Ensino técnico: desempenho e custos. Rio de Janeiro: IPEA, 1972.

CONLEY, D. T.; PICUS, L. O. Oregon's quality education model: linking adequacy and outcomes. Educational Policy, v. 17, n. 5, p. 586-612, nov. 2003.

DIAZ, M. D. M. Qualidade do gasto público municipal em ensino fundamental no Brasil. Revista de Economia Política, São Paulo, v. 32, n. 1, p. 128-141, jan./mar. 2012.

FARENZENA, N. (Org.). Custos e condições de qualidade da educação em escolas públicas: aportes de estudos regionais. Brasília: INEP/MEC, 2005.

GALVÃO, F. V. Gastos com educação e desempenho escolar: uma análise no nível da escola. 2016. Dissertação (Mestrado em Educação) - Universidade de São Paulo, São Paulo, 2016.

GALVÃO, F. V. Gastos com salários e desempenho em matemática: uma análise baseada nas escolas municipais de SBC. Educação e Pesquisa, São Paulo, v. 44, 2018.

GOUVEIA, A. B.; CRUZ, R. E.; OLIVEIRA, J. F.; CAMARGO, R. B. Condições de trabalho docente, ensino de qualidade e custo-aluno-ano. Revista Brasileira de Política e Administração da Educação, v. 22, n. 2, p. 253-276, jul./dez. 2006. 
A Pesquisa sobre Custo-Aluno no Brasil

LEVY, S.; CAMPINO, A. C.; NUNES, E. M. Análise econômica do sistema educacional de São Paulo. São Paulo: IPE - USP, 1970.

MARTINS, E. Contabilidade de custos. São Paulo: Atlas, 2003.

MENEZES-FILHO, N.; OLIVEIRA, A. P. A relação entre gastos em educação e desempenho escolar nos municípios brasileiros: uma análise com dados em painel. In: FERNANDES, R.; SOUZA, A. P. F.; BOTELHO, F.; SCORZAFAVE, L. G. (Org.). Políticas públicas educacionais e desempenho escolar dos alunos da rede pública de ensino. São Paulo: Funpec, 2014.

MONTEIRO, J. Gasto público em educação e desempenho escolar. Revista Brasileira de Economia, Rio de Janeiro, v. 69, n. 4, p. 467-488, 2015.

ODDEN, A.; ARCHIBALD, S.; FERMANICH, M.; GROSS, B. Defining school-level expenditure structures that reflect educational strategies. Journal of Education Finance, v. 28, n. 3, p. 323-356, 2003.

OLIVEIRA, J. F. Escolas públicas de qualidade em Goiás: custo-aluno-ano e outras condições para oferta de ensino. In: GOUVEIA, Andréa B.; SOUZA, Ângelo R.; TAVARES, Taís M. (Org.). Conversas sobre financiamento da educação. Curitiba: Ed. da UFPR, 2006.

OLIVEIRA, R. P.; ARAUJO, G. C. Qualidade do ensino: uma nova dimensão da luta pelo direito à educação. Revista Brasileira de Educação, Brasília, n. 28, jan. labr. 2005. Disponível em: http://www.scielo.br/scielo.php?script=sci_arttext\&pid=\$1413-24782005000 100002\&lng=pt\&nrm=iso. Acesso em: 19 dez. 2019.

PARO, V. H. Estudo comparativo de custo-aluno nos diversos graus e modalidades de ensino. São Paulo: ATPCE: FCC, 1981.

PICUS, L. O. Student-level finance data: wave of the future? The Clearing House, New York, v. 74 , n. 2 , p. $75-80$, nov./dec. 2000.

PICUS, L. O.; ODDEN, A.; APORTELA A.; MANGAN, M. T.; GOETZ, M. Implementing school finance adequacy: school level resource in Wyoming following adequacy-oriented finance reform. California: Lawrence O. Picus and Associates, 2008.

PICUS, L. O.; PETERNICK, L. Developing student resource variables for the early childhood longitudinal survey. Developments in school finance, Washington D. C., National Center for Education Statistcs, p. 107-128, 1998.

PINTO, J. M. R. Uma proposta de custo-aluno-qualidade na educação básica. Revista Brasileira de Política e Administração da Educação, v. 22, n. 2, p. 197-227, jul./dez. 2006.

ROCHA, A. B.; FUNCHAL, B. Mais recursos, melhores resultados? As relações entre custos escolares diretos e desempenho no Ensino Médio. Revista de Administração Pública, Rio de Janeiro, v. 53, n. 2, p. 291-309, 2019.

ROSS, K. N.; LEVACIC, R. Needs-based resource allocation in education via formula funding of schools. Paris: UNESCO, 1999.

SCHULTZ, T. W. Capital formation by education. The Journal of Political Economy, Chicago, v. 68, n. 6, p. 571-583, dec. 1960. 
A Pesquisa sobre Custo-Aluno no Brasil

SCHULTZ, T. W. O valor econômico da educação. Rio de Janeiro: Zahar Editores, 1967.

SCHWARTZ, A. E.; RUBENSTEIN, R.; STIEFEL, L. Why do some schools get more and other less? An examination of school-level funding in New York City. Working Paper 09-10. Institute for Education and Social Policy, 2009.

SILVA, L. M. Contabilidade Governamental: um enfoque administrativo da nova contabilidade pública. São Paulo: Atlas, 2009.

SMITH, A. A riqueza das nações: investigação sobre sua natureza e suas causas. São Paulo: Nova Cultural, 1996.

VERHINE, R. E. Custo-aluno-qualidade em escolas de educação básica. Brasília: INEP, 2006.

VERHINE, R. E.; MAGALHÃES, A. L. F. Quanto custa a educação básica de qualidade? Revista Brasileira de Política e Administração da Educação, v. 22, n. 2, p. 229-252, jul./dez. 2006.

XAVIER, A. C. R.; MARQUES, A. E. S. Custo direto de funcionamento das escolas públicas de $1^{\circ}$ grau da região sul. Brasília: MEC/SEB, 1988.

Fernando Vizotto Galvão é doutorando em Educação pela Faculdade de Educação - USP. Mestre em Educação pela Faculdade de Educação - USP (2016). Possui graduação em Economia pela Faculdade de Economia, Administração e Contabilidade - USP (2008). Atua como Especialista em Políticas Públicas no Governo do Estado de São Paulo desde 2010.

ORCID: http://orcid.org/0000-0001-7967-0477

E-mail: fernando.galvao@usp.br

Recebido em 02 de fevereiro de 2020

Aprovado em 31 de março de 2020 


\section{Editores do volume 11}

Márcia Aparecida Jacomini - Universidade Federal de São Paulo, Brasil

José Marcelino de Rezende Pinto - Universidade de São Paulo, Brasil

\section{Comitê Editorial}

Nalú Farenzena - Universidade Federal do Rio Grande do Sul, Brasil

Juca Gil - Universidade Federal do Rio Grande do Sul, Brasil

Theresa Adrião - Universidade Estadual de Campinas, Brasil

Ângelo Ricardo de Souza - Universidade Federal do Paraná, Brasil

\section{Conselho Editorial}

\section{Alejandro Morduchowicz}

Universidad Pedagógica, Provincia de Buenos Aires, Argentina

Andréa Barbosa Gouveia

Universidade Federal do Paraná, Brasil

Fernanda Saforcada

Universidade de Buenos Aires, Argentina

Jacques Velloso

Universidade de Brasília, Brasil

João Monlevade

Senado Federal, Brasil

Jorge Abrahão de Castro

Instituto de Pesquisa Econômica Aplicada / IPEA, Brasil

Lisete Regina Gomes Arelaro

Universidade de São Paulo, Brasil

Luis Carlos Sales

Universidade Federal do Piauí, Brasil

Luiz de Sousa Junior

Universidade Federal da Paraíba, Brasil

Luiz Fernandes Dourado

Universidade Federal de Goiás, Brasil

Magna França

Universidade Federal do Rio Grande do Norte, Brasil

Marcos Edgar Bassi

Universidade Federal de Santa Catarina, Brasil

Maria Angélica Pedra Minhoto

Universidade Federal de São Paulo, Brasil

Maria Beatriz Luce

Universidade Federal do Rio Grande do Sul, Brasil

Maria Dilnéia Espíndola Fernandes

Universidade Federal de Mato Grosso do Sul, Brasil

Nelson Cardoso do Amaral

Universidade Federal de Goiás, Brasil

Nicholas Davies

Universidade Federal Fluminense, Brasil

Robert E. Verhine

Universidade Federal da Bahia, Brasil

Romualdo Portela de Oliveira

Universidade de São Paulo, Brasil

Rosana Gemaque Rolim

Universidade Federal do Pará, Brasil

Rubens Barbosa de Camargo

Universidade de São Paulo, Brasil

Theresa Adrião

Universidade Estadual de Campinas, Brasil

Tristan McCowan

University of London, Reino Unido

Vera Jacob

Universidade Federal do Pará, Brasil

Vera Peroni

Universidade Federal do Rio Grande do Sul, Brasil

Vitor Henrique Paro

Universidade de São Paulo, Brasil

\section{Equipe editorial}

Apoio ao Comitê Editorial: Caio Cabral da Silva

Diagramação, Revisão de português e normalização: Edson Leonel de Oliveira

Revisão de inglês: Sabrina Ferreira

Fineduca - Revista de Financiamento da Educação

Associação Nacional de Pesquisa em

Financiamento da Educação

e-mail: revista.fineduca@gmail.com | site: http://seer.ufrgs.br/fineduca 